\title{
PROFILE
}

\section{Guru of graphic medicine}

I wan James is a "neurotic but empathic" middle-aged general practitioner in Britain. He frequently has flashbacks to his youth, when he suffered from obsessivecompulsive disorder. When feeling particularly depressed or confused, he imagines putting a gun to his head. "Constantly questioning," Dr. James wonders whether he is truly helping his patients or if he is "The Bad Doctor."

This description of the fictional Iwan James comes from his creator, the very real Ian Williams, a part-time general practitioner in Brighton, on the south coast of England, and an almost full-time practitioner of graphic medicine: the use of comics and illustrated stories, often with black humour, to educate doctors and their patients about particular medical issues. The neurotic Dr. James is the central character in Williams' much praised graphic novel The Bad Doctor, the first in a planned trilogy. Next up in 2017 is The Lady Doctor (an "ironic title"), about a female physician who caught the eye of the married Dr. James in the first book. Number three is still being planned.

Physicians, rather than patients, are the target audience for Williams' literary dissections of doctor-patient interactions, he said in a telephone interview. Maybe, just maybe, doctors will see the pluses and minuses of how the fictional Dr. James handles difficult, demanding patients and learn how best to deal with such situations. Did Dr. James really deal appropriately with the scary guy who needed a physician's okay to get a gun licence or with the elderly widower threatening suicide because of his wife's death? Certainly, Dr. James is unsure if he did the right thing (Appendix 1, available at www.cmaj.ca/lookup/suppl/ doi:10.1503/cmaj.160027/-/DC1).

First published in Britain in 2014, The Bad Doctor came to North America

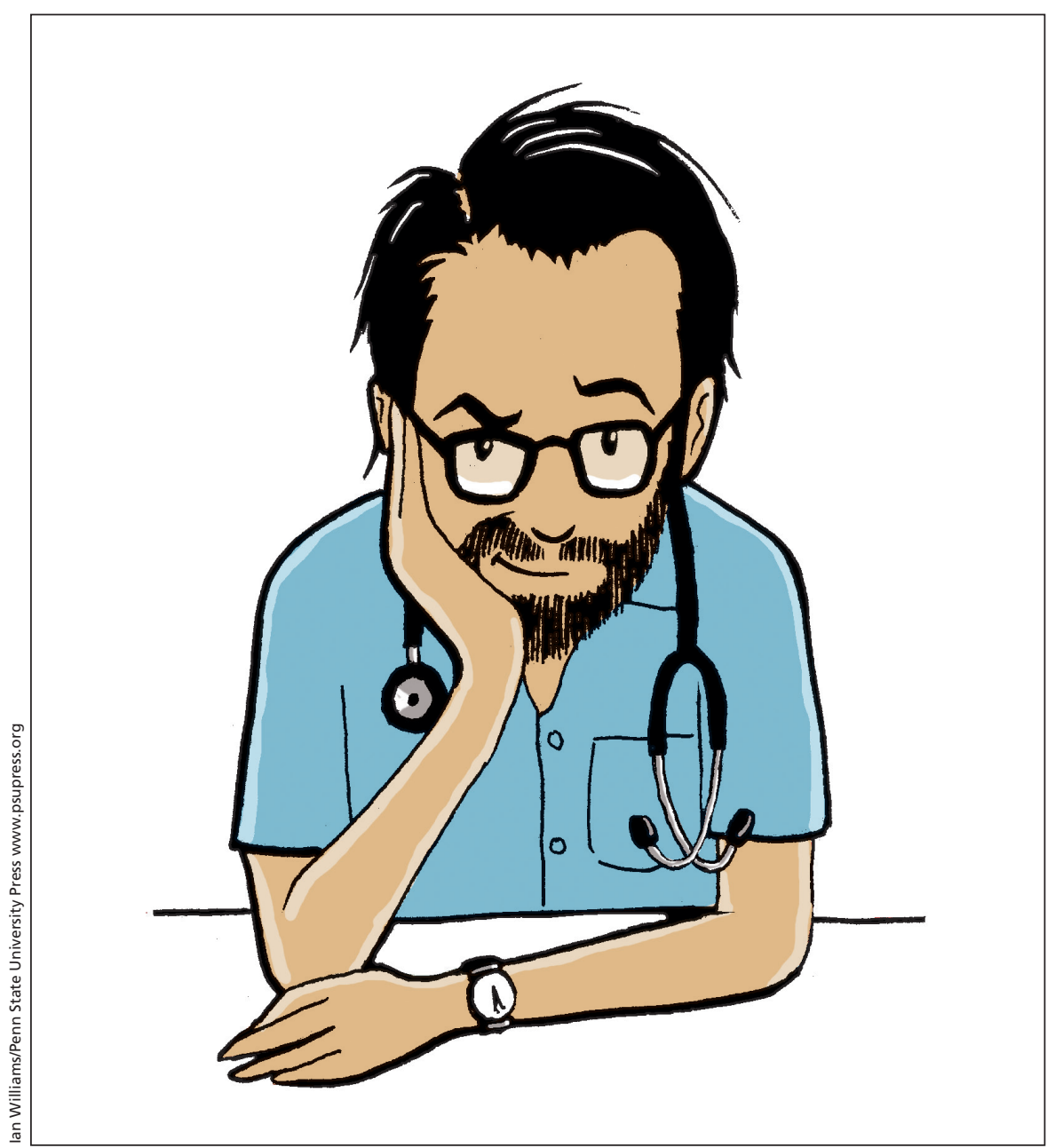

Ian Williams has been able to combine his interest in medicine and art through his pioneering work in graphic medicine.

in 2015 courtesy of Penn State University Press and received a warm welcome from, among others, The New York Times, which praised the book as "subtle and thought-provoking" and among the "best" of its kind. A French-language version, Les bleus de medecine, has since been published by Marabout.

Williams had initially thought of writing an autobiographical book but realized "my story is not that exciting." So, he created Iwan James. The two are both prone to brooding melancholy and a dark sense of humour. And, like the fictional doctor, the real one also suffered from obsessive-compulsive disorder as a youth. Although Williams says he has overcome that condition, it does appear he is a man obsessed, albeit healthily, with graphic medicine.

Graphic novels are just part of that apparent obsession. He founded, in 2007, the website graphicmedicine. org, a meeting place for the growing international community interested in comics and medicine. Williams draws and writes a weekly comic strip called "Sick Notes" for the daily newspaper 
The Guardian, often lampooning the foibles of Britain's National Health Service (NHS). In one "Sick Notes" offering, a doctor rages against a supposed NHS directive to save it money by encouraging male patients to use condoms rather than to seek vasectomies. Nevertheless, Williams says he would "hate" to work in the more private-sector-controlled American health system. Williams also serves on the boards of various medical humanities organizations and is an editor for a series of graphic medical books from Penn State University Press. because of a doctor's evil fantasies about harming patients.

Williams was interested in both medicine and art from an early age but, as a student, pursued medicine, at least in part because of a more assured income. He graduated from Cardiff University in 1989, and two years later, during a six-month appointment in New Zealand, developed an irresistible urge to start painting. Upon returning to Wales in 1992, Williams began exhibiting. "I made some money at it," he says. Initially, he created landscapes and turned them into prints.

\section{Williams suddenly realized there was a way to combine his interests in art and medicine.}

Involvement in graphic medicine is so consuming that Williams says he no longer has the time to climb mountains, ski and cycle as he did when he was a full-time doctor for 15 years in Wales. Living in flat, seaside Brighton seems to have removed him both physically and psychologically from mountainous pursuits. In Brighton, Williams shares a home with his girlfriend and fellow writer, Emma Jane Unsworth, whose latest novel to reach Canada is called Animals. Publisher HarperCollins describes the story's two protagonists as "young women who have been tearing up the city streets for ten years, leaving a trail of angry drug dealers and spent men in their wake." They sound like the kind of patients who bring their problems to The Bad Doctor, causing him to tear out his hair seeking the right advice.

Michael Green uses Williams' comics in a graphic medicine course he teaches at the Penn State College of Medicine. "Ian's a real pioneer," says Green. "He coined the term graphic medicine." Green has collaborated with "the honest, funny and engaging" Williams on a few projects and insists the Briton is not as dark as the humour in his books, notably the very dark Disrepute, a compilation of comics written under the penname Thom Ferrier. Disrepute is a 2012 book that tends to shock medical students
Later, he produced landscape-inspired, minimalist abstracts.

But there were problems. Williams was frequently asked to discuss his art. That made him uncomfortable. "It should speak for itself," he says. Williams also had difficulty with the dual roles of artist and doctor. "It was an effort to try and marry the two sides of my career."

A genuine "life-changing" moment came in 2006. "The thing that twigged for me was I was in the Tate Modern in London in their bookshop," Williams recalls. "I found Brian Fies' book Mom's Cancer. I found it amazing." Upon reading the book about one cancer patient's battles with the medical establishment, Williams suddenly realized there was a way to combine his interests in art and medicine. He found his calling in graphic medicine. "I needed to do this whether or not I made any money."

With his new obsession, Williams started drawing cartoons and reading medical comics by the likes of Chris Ware and Daniel Clowes, reviewing them on graphicmedicine.org. Likeminded people started writing to him. He went back to school, earning a master's in medical humanities at Swansea University in 2009 with a dissertation on graphic medicine. The next year, he helped organize the first of a continuing series of annual international conferences on graphic medicine. That initial gathering in 2010 was held in London; later ones were held in Chicago, Toronto, Brighton, Baltimore and Riverside, California; the 2016 conference is to be in Dundee, Scotland. The number of conference participants grows each year and becomes more "academic" in tone, says Williams. "It's very exciting."

Williams is attracted to graphic novels because of their playfulness and dark humour; they criticize aspects of health care "in a questioning way, not a damning way." These books can also reveal truths unattainable in straight nonfiction. (The late Canadian author Farley Mowat had a similar attitude, admitting his "nonfiction" sometimes — and controversially — fudged facts to attain that supposed "larger truth.") "With prose, people get hung up on their truthfulness," says Williams. "When people have written autobiographical experiences, there's something about it being in words that makes people more likely to challenge it, whereas [with] comics, being more playful and a more constructed medium, people don't worry so much about what things are exactly true."

For Williams, a prime goal of graphic medicine is to improve communications between physicians and patients in such critical situations as delivering a cancer diagnosis. Many doctors are like the fictional Iwan James and wonder whether their methods make them a good or bad doctor, says Williams. But many doctors don't ask those questions, they being the very ones who need "communication education," the ones most in need of a dose of graphic medicine. Green agrees: "The ones who don't have any selfdoubts are the ones I worry about."

\section{Paul Gessell}

Art Critic, Ottawa, Ont.

CMAJ 2016. DOI:10.1503/cmaj.160027 